\title{
Low innovation among building material suppliers: the natural level of the trade?
}

Jan Sundqvist, MSc (Doctoral Student,Örebro University, Sweden)

\section{ABSTRACT}

Many studies concerning innovation have been carried out on building contractors, but very few have studied innovation among the suppliers of building materials. In Sweden the cost of building materials is approximately $40 \%$ of the total building costs. Some products also need more handling than others, therefore not only cost but also productivity is affected by the suppliers of building materials. This article focuses on innovation among building material suppliers, which is found to be low. The suppliers are compared to other lines of business to show the level of their innovation processes. The article is based upon slightly over 800 companies of various sizes. Important findings are:

- A smaller proportion of the Building Material Suppliers than of the Other Manufacturers offer new products, invest in R\&D, machinery and marketing the introduction of products.

- The Building Material Suppliers have a greater proportion of their sales from older products and have older equipment than the Other Manufacturers.

- The Building Material Suppliers have poorer production processes and they are not as good at finding new ideas as the Other Manufacturers.

- The study reveals barriers within the trade, where motivation seems to be of great importance.

Key words: innovation, processes, building material suppliers, new products, development

\section{INTRODUCTION}

Innovation in the building trade is often described from the point of view of construction companies. Winch (2003) has stated that the contractors have not innovated enough. They have, he says, fallen behind the rest of the manufacturing industry in terms of productivity, quality and value for money. He also claims that there are difficulties in measuring innovation. Any comparison, he says, of industry performance using data organized in SIC (Standard Industrial Classification) categories must either encompass the whole value system for each industry compared, or compare only the same parts of the value system (Winch, 2003). Winch also states, that the value chain, as measured by the SIC, cuts out a lot of construction innovation. "Product innovation is, in essence, a design activity, so this is largely the responsibility of A-sector firms, not Bsector firms. The SIC for construction on the other hand excludes A, but includes all firms engaged in B, C, D" (Winch, 2003: 653). This is quoted to point out the problems in the construction sector when measuring innovation according to SIC.
In this study a different approach to SIC has been used. The study is based upon a methodology developed in Australia and New Zealand. More about it can be read under the heading "performance of the study".

The suppliers of building materials are very seldom subjected to research. Their level of innovation is therefore not known. The purpose of the study described in this paper was to determine to what extent manufacturers use the best practices, and then to identify areas in which a firm needs to make improvements. The aim of the article is to describe shortcomings concerning innovation processes and to suggest further research.

Companies have different roles in the supply chain. Building material suppliers, that is, material, component and process equipment manufacturers upstream in the supply chain are developing products that will be used by construction companies in building projects. Andersson et al. (1983) termed these types of companies "basic technology companies" and their business ideas are built on a continuously ongoing innovative development of their products. They are working with products that are under development, under rapid growth, in a mature phase or in a terminating phase which fit into the well known S-shaped development curve. These companies manufacture products which follow the product life cycle and they have other development and innovation possibilities than the project-orientated construction companies.

"The innovation research field, in the construction firm context, is thus still very much in its embryonic stage. Innovation theory and practice are being drawn from established bodies of innovation knowledge predominately based on other industries but they have not been sufficiently envisioned, embedded and evaluated in a construction context to form a robust body of construction innovation knowledge in its own right " (Barrett and Sexton, 2003: 614).

I agree with the observation that:

"[construction] project-based, service-enhanced forms of enterprise are inadequately addressed in the innovation literature" (Gann and Salter, 2000: 955).

The building material suppliers affect much more on the construction site than we normally think of. Not only the products themselves can be affected but also the tools and other facilities developed by the supplier for the assembly of the products on site. This means that the workers, indirectly, are affected. From this also follows that the cost of working hours plus the cost of the product is affected. From this we can 
conclude that the building material suppliers not only affect the product itself, but also the productivity.

This article focuses innovation among building material suppliers. It is made as a comparison between two groups of companies. The building material suppliers are placed in one group. All the other manufacturing companies will be found among the "Other Manufacturers"

\section{CULTURE AND MOTIVATION AMONG THE BUILDING MATERIAL SUPPLIERS}

The behaviour of the companies from the building sector differs from the companies from other sectors. This has been seen before, for instance in DIST (1998), and in SOU (2000). These are just two examples, one from Australia and one from Sweden. While other sectors modernized through the introduction of interchangeable parts, to assembly lines, and then to automation, construction retained its craft method of operation and fell further and further behind the rest of the manufacturing industry in terms of productivity, quality, and, hence, value for money. In other word it did not innovate (Winch, 2003). The suppliers seem to follow the same path.

It is, however, too easy to complain about the "Building Material Suppliers" and say they perform poorly. That has been said many times before and nothing have really happened after these complaints.

There must be something about the building-related industry, which all the actors have in common. The building industry has old traditions. It has been protected against foreign competition and there are old traditions in governmental subsidies to housing. Innovation is low among the suppliers as well as among the construction companies. They also both have craft methods of operation (Winch, 2003). They act more or less in the same way, which differs substantially from the "Other Manufacturers". Each company seems to act upon what it assumes to be best in the short run. It is often argued that engineering companies act rationally when they invest, because it usually strengthens the competitive edge of the company. In the same way, it ought to be rational, when companies do not innovate. From the spectator's point of view, on the other hand, the behaviour of the "Building Material Suppliers" might seem quite irrational. Our understanding of the situation depends on our viewpoint - inside or outside the company.

In this study some managing directors were also interviewed. Some of them mentioned culture factors, which they argued were negative for the trade. It is hard, they said, to make changes and to bring new ideas forward. Old ways of thinking among the employees make barriers for us, they said. Indeed, it has been argued that the construction industry is infamous for the barriers it places in the way of innovation (Sexton et al., 2003). Culture refers to the shared values and beliefs that shape the way that people communicate and work. Culture is reflected in people's attitudes and evidence indicates that they are largely sceptical towards innovation in the building and construction industry and see it as someone else's responsibility (Lenard, 1996). For example, Loosemore (2004) found a widespread belief amongst consultants and contractors that the primary responsibility for both product and process innovation lay with subcontractors and manufacturers respectively.

Most of the suppliers operate on a local or regional basis. Their customers are the contractors, small as well as large ones. In general, innovation is perceived as an academic activity, which in most instances produces theoretical results of little commercial value (Loosemore et al., 2002). The perception is that relatively few new ideas furnish commensurate benefits and that they produce unsatisfactory rates-of-return and few improvements in competitiveness. Furthermore, many employees in the building and construction industry have been failed by the traditional classroom-based educational system and perceive learning as a non-productive activity and associate it with failure (Loosemore, 2004).

Innovation is low even in large companies (Larson et al., 2003). The suppliers in general are not used to innovating. They give the impression that they will continue in the same way as before. They know that way. And as innovation is rare, which is seen in the survey, there is not much change in competition on the market. As the companies do not innovate, they can concentrate on survival, which means acting on a short term base. We can read in articles and literature that the contractors do not seem interested in innovation (DIST, 1998; SOU, 2000). The competition in the building sector is static. The renewal of products and production processes is low. Companies that are established on the market mainly compete with existing technology and therefore do not contribute to development (SOU, 2000). One could ask what their motivation to innovate is. The companies will still have their sales, even when deliveries are late and not complete. The findings give us a picture of rather poor timelines. But the customers do not have any alternative, because there are no other companies to replace the poor ones. So are there really any motives to innovate? They will get the orders any way. Many of them probably have no experience in finding out what products or processes to improve either, because they are not used to dealing with market information, as was discussed earlier.

However, companies that continuously improve their offerings do get improved performance (Easton et al., 2001). The question of motivation seems very relevant. According to Sexton et al. (2003), there are gaps in understanding what the general motivation to innovate is.

\section{PERFORMANCE OF THE STUDY}

This article is based on a study of Swedish companies called "Insikter för framgång" (2002). The study is based on a methodology developed by the Australian manufacturing council and the New Zealand Government's benchmarking studies for small manufacturing firms, entitled Leading the Way (1994) and Gearing Up (1997) and subsequent issues of the latter. The Swedish study has used the same questions that the New Zealand Government used in their recent study Firm Foundation (2002). This was done to make it possible to compare manufacturing companies and trades in the two 
countries. There are many similarities between Sweden and New Zealand. Both are fairly small countries, are deregulated to a large extent. Both countries have a large number of small businesses.

The study was designed to determine to what extent manufacturers use the best practices and then to identify areas in which a firm needs to make improvements to ultimately become a world class enterprise. The study, as such, looks at precisely the same areas of business practices that have been identified in the various international quality awards.

Supply of building material represents about $40 \%$ of the total production costs for a building project in Sweden. Each product group in the building material market is dominated by few manufacturers and vertical integration is common (SOU, 2000). Price is a dominating competitive instrument and a relatively small amount of building material is imported. The development of building material is thus one of the most crucial issues for the development of the building sector - a sector that is so often accused of being conservative and non-innovative. However, suppliers of material, components and processing equipment to building projects comprise one of the most neglected actor categories in research about management and development in the construction sector.

\section{THE SWEDISH STUDY}

An extensive excellence study on manufacturing companies has been carried out in four Swedish regions (Insikter för framgång, 2002). This paper contains data from two of those regions - one rural area (Örebro) and one from a large city (Gothenburg). Manufacturing is strong and diverse in both regions. The data is presented as comparisons between two groups - the "Building Material Suppliers" and the "Other Manufacturers". The first group is also called BMS and the latter $\mathrm{OM}$. The latter group contains all other manufacturing companies in the regions. All companies in the study have 10 or more employees.

The province of Örebro has approximately 260000 inhabitants and 304 manufacturing companies with at least 10 employees and Gothenburg approximately 450000 inhabitants and 536 manufacturing companies with at least 10 employees. Large companies very often have many sites and in order to bring these into the investigation, sites were looked upon as individual companies. The response rate in the province of Örebro (Sundqvist, 2002) was 50\% (153 replies) and 39\% (208 replies) in Gothenburg (Persson et al., 2002). In total 361 companies responded to the questionnaire. The OM group contains all companies that are not defined as building material producers, see Figure 1.

\begin{tabular}{|l|c|c|}
\hline Companies & $\begin{array}{l}\text { Building } \\
\text { Material } \\
\text { Suppliers }\end{array}$ & $\begin{array}{l}\text { Other Manu- } \\
\text { facturers }\end{array}$ \\
\hline Small companies & 19 & 207 \\
Medium sized companies & 15 & 89 \\
Large companies & - & 32 \\
\hline & 34 & 327 \\
\hline
\end{tabular}

Figure 1: Companies (Small companies 10-49, medium sized 50-249 and large >250 employees. This definition is used within the EU.)

The total study is based upon a questionnaire, which contains 220 questions. In this paper we have chosen questions that are related to innovation, which are 47 out of the total of 220 .

Findings from the Survey: The Building Material Suppliers are lagging behind

Innovation \& technology - the source of new methods of production and of new products and services - turned out to be the weakest of the seven processes studied. Only the leading and the large companies in Sweden scored well in the process of innovation. Export-orientated firms also did well. Why are the innovation \& technology processes so poor?

It is noticeable, see Figure 2, how much the companies related to the building industry differ from other lines of business. 


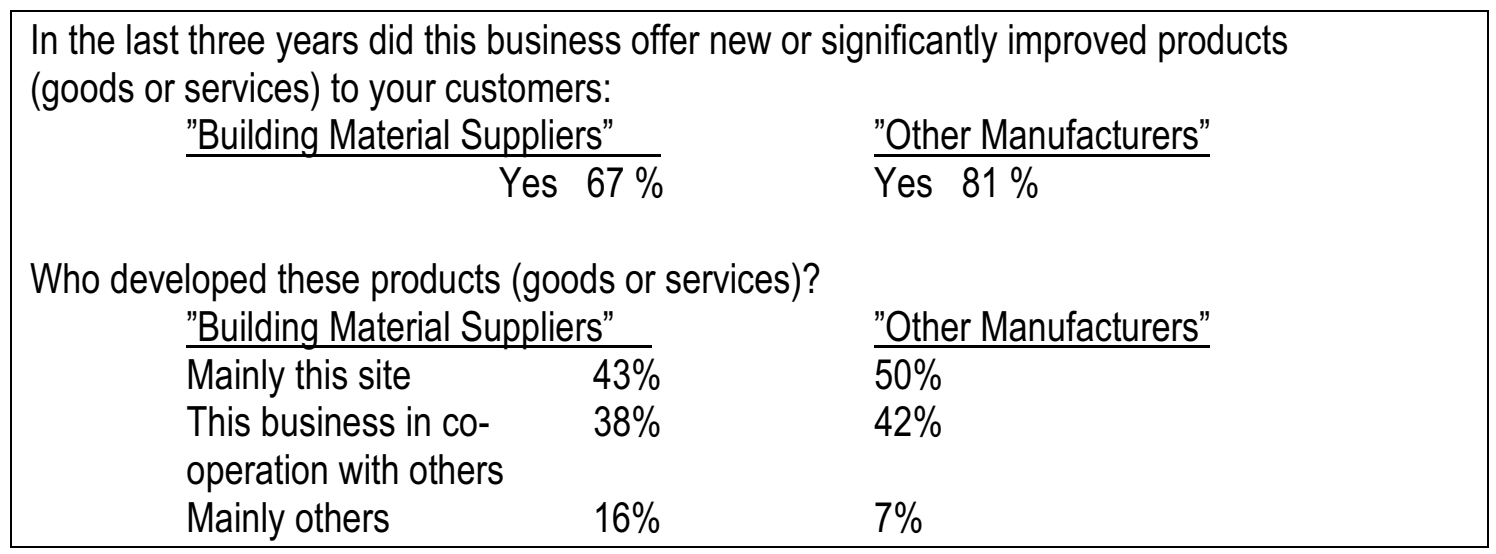

Figure 2: New or significantly improved products

The two questions in Figure 2 show that there is a difference between the two groups. A smaller share of the BMS companies $(67 \%)$, than the OM companies $(81 \%)$, state that new or significantly improved products are offered. The group of
"Other Manufacturers" use more of their internal skill, as they have a larger proportion of "mainly this site" and "this business in cooperation" and a smaller proportion of "mainly others". This tells us that the OM companies have more developed processes for finding and bringing new ideas forward.

In the last three years did this business introduced new or significantly improved processes including new ways to supply services or deliver products:

"Building Material Suppliers"

"Other Manufacturers"

Yes $36 \%$

Yes $68 \%$

Who developed these processes:

"Building Material Suppliers"

\begin{tabular}{lcc}
\hline Mainly this site & $58 \%$ & $51 \%$ \\
This business in co- & $32 \%$ & $42 \%$ \\
$\begin{array}{l}\text { operation with others } \\
\text { Mainly others }\end{array}$ & $5 \%$ & $7 \%$
\end{tabular}

Figure 3: New or significantly improved processes

In Figure 3 we can see that not only products and development lack attention, but also production processes. Processes are only improved among $36 \%$ of the "Building Material Suppliers" compared to $68 \%$ of the companies in the group of "Other Manufacturers". This strengthens the findings from Figure 2, saying that the BMS lack the know-how to find new ideas and bring them forward. On the other hand, the companies that did develop seem to have the knowledge, if not internally, then at least in cooperation with others. 


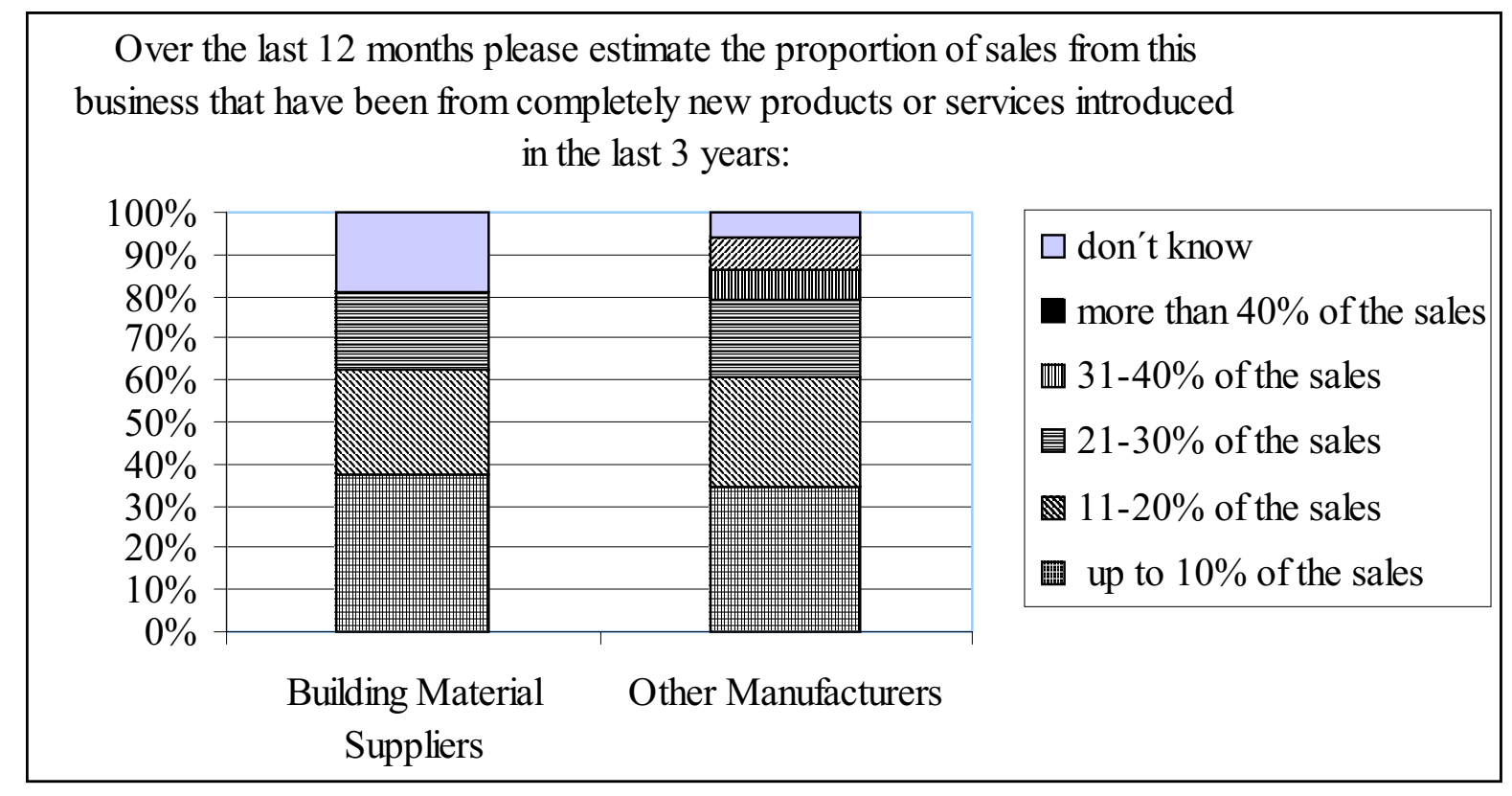

Figure 4: Sales from completely new products introduced $s$ in the last 3 years.

From Figure 4 one can see that, for the "Other Manufacturers", a larger proportion of their sales comes from completely new products than for the "Building Material Suppliers". The BMS companies are also more uncertain about the age of their products. "More than $31 \%$ of the sales from new products" are achieved by approximately $16 \%(8 \%+8 \%)$ of the group of
"Other Manufacturers". None of the BMS companies reach "31\% of the sales from new products". The result is not surprising. In Figure 2 we saw that the "Other Manufacturers" have developed more new products than the "Building Material Suppliers". Figure 5 will show the same thing, but from a somewhat different angle

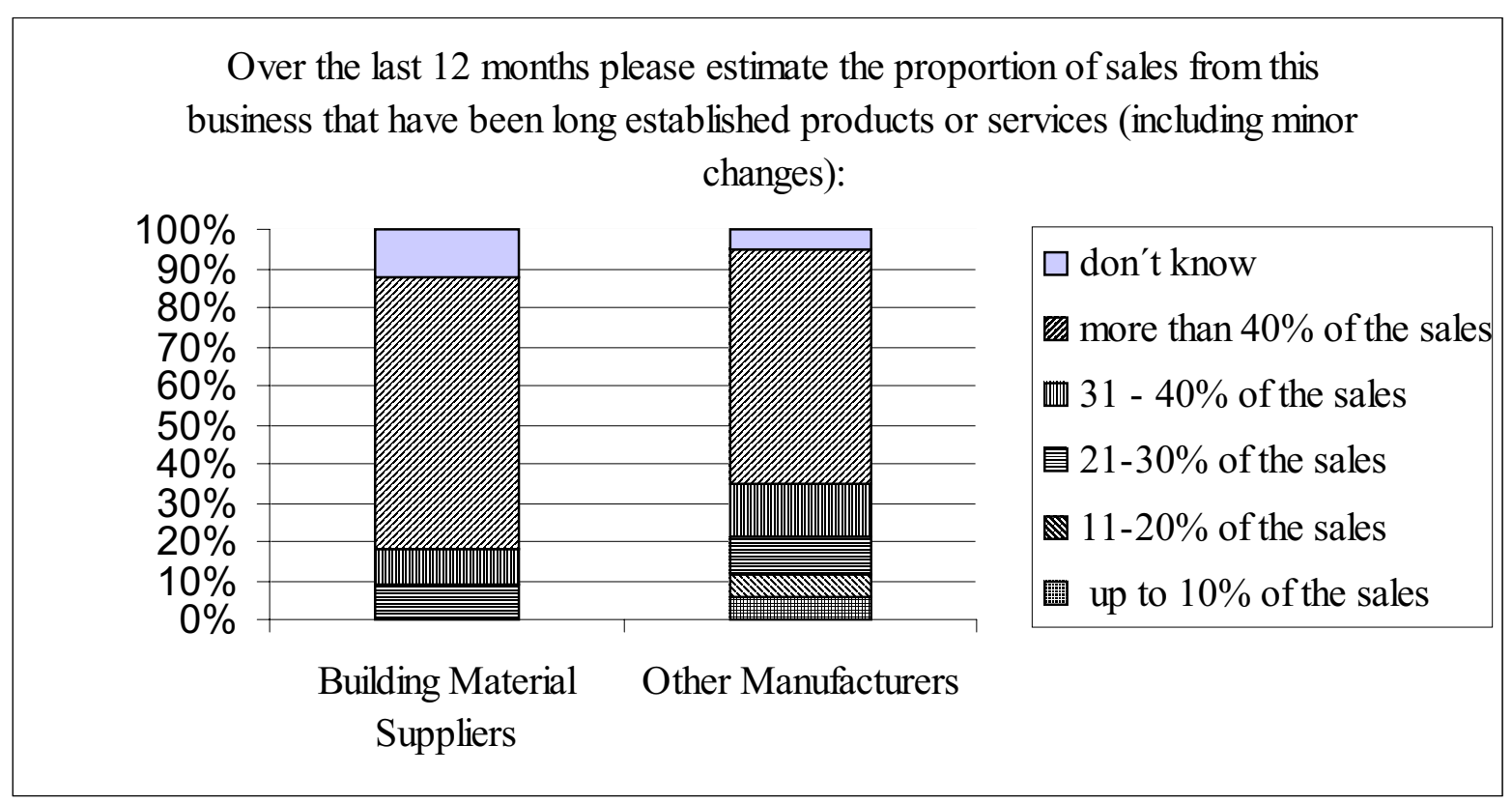

Figure 5: Sales from long established products. 
The "Building Material Suppliers" have a greater share of their sales from older products than the "Other Manufacturers" have. When the category "more than $40 \%$ of the sales" is studied, a $10 \%$ difference can be noticed between the two groups. By adding the figures from the start a rather clear picture can be obtained. The BMS companies have not developed as much as the OM companies have. One assumption that could follow from this is that the group related to the construction companies have older equipment, because established products often mean old products and old equipment. Use of equipment and available technology is shown in Figure 6

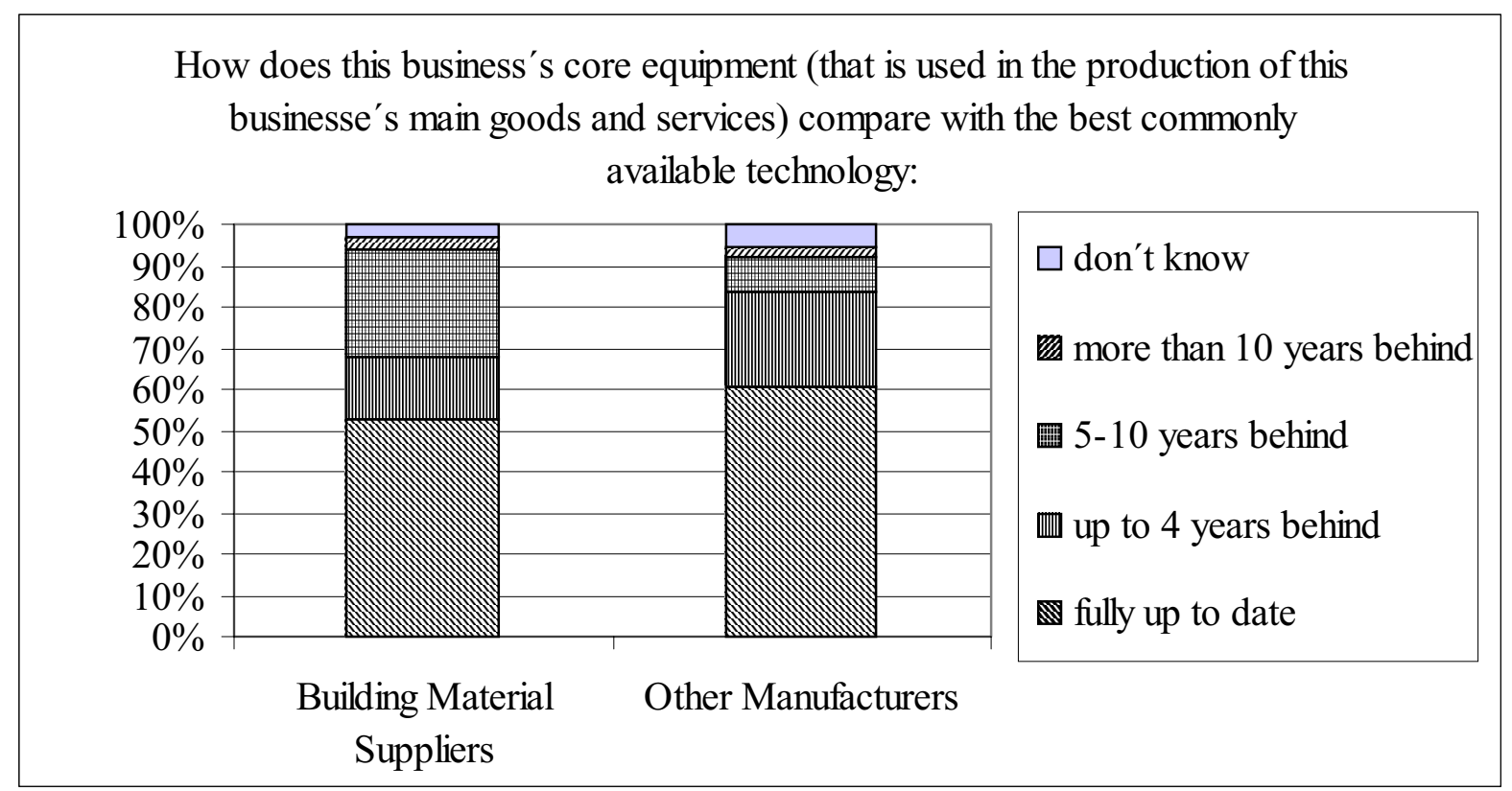

Figure 6: Core equipment compared to best commonly available technology

The "Building Material Suppliers" have older equipment than the "Other Manufacturers" have. Fully up to date are $53 \%$ of the BMS compared to $61 \%$ of the OM, and up to 4 years behind are $15 \%$ of the BMS compared to $23 \%$ of the OM. This means in total that $68 \%$ of the "Building Material Suppliers" have equipment that is at the most 4 years old compared to $84 \%$ of the "Other Manufacturers". Among the BMS a large proportion of companies, $25 \%$, are found to have machinery that is up to 10 years old. So far we have noticed a difference in terms of developing new products and having fully up to date equipment.

The next question, which is shown in Figure 7, deals with companies that actually have invested in development or in marketing the introduction of products.

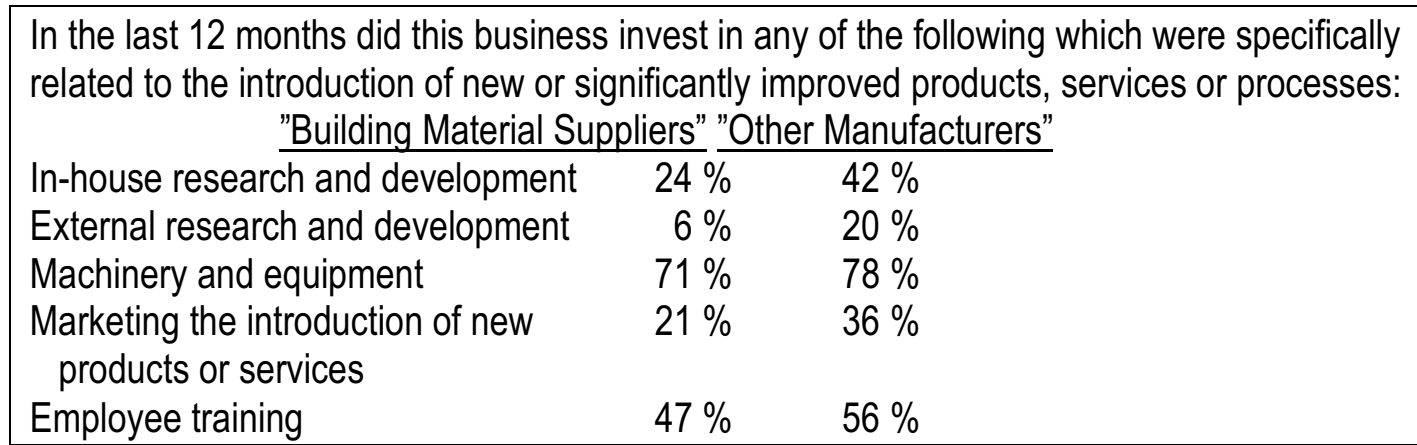

Figure 7: Investments in the last 12 months. 
Differences in development were expected from the figures above, but not the extent of the differences. We read that $24 \%$ of the "Building Material Suppliers" had invested in internal product development and $6 \%$ external, compared to $42 \%$ internal and $20 \%$ external of the "Other Manufacturers". The total picture of the investments is that there is a smaller proportion of companies investing among the "Building Material Suppliers" than among the "Other Manufacturers". The "Building
Material Suppliers" invest considerably less in R\&D, internally as well as externally, in marketing, in employee training and equally less in machinery. This also explains or at least gives more background to the figures above.

The next question in our survey is how much is invested. Investments are shown in Figure 8.

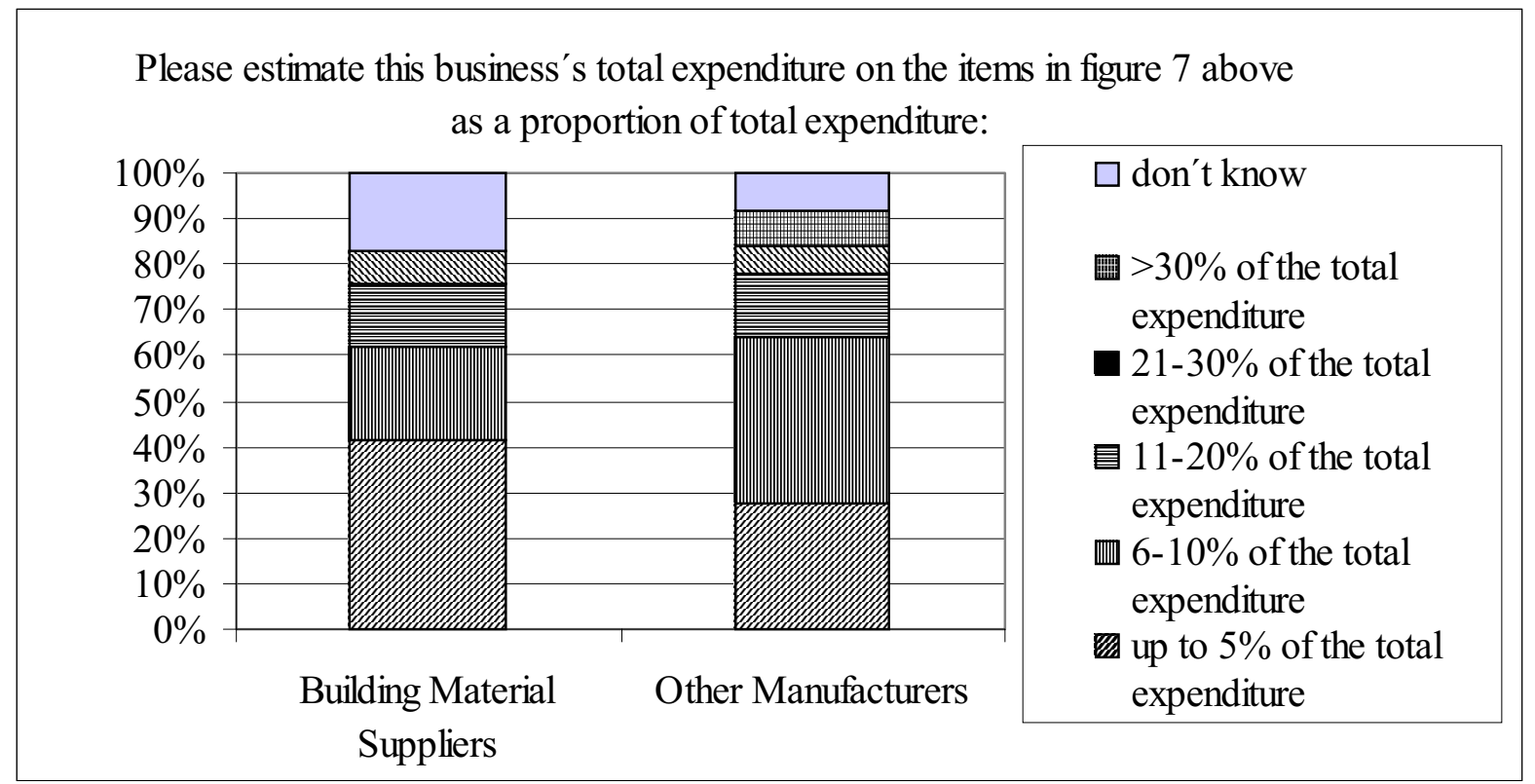

Figure 8: Expenditure of investments (figure 7) in the last 12 months.

The findings from previous figures correspond with Figure 8. There is a larger proportion of companies from the "Building Material Suppliers" that invest less than the group of "Other Manufactures". Less investment, as could be seen in Figure 7, implies less expenditure. Therefore the findings in Figure 8 were expected. The "Building Material Suppliers" have a lower level of investment in development, machinery, employee training, and marketing of new products.

\begin{tabular}{|c|c|c|}
\hline \multicolumn{3}{|c|}{$\begin{array}{l}\text { In the last three years did this business or business's parent company use an } \\
\text { of the following methods to protect inventions developed by this business: }\end{array}$} \\
\hline \multicolumn{2}{|c|}{ "Building Material Suppliers" } & "Other Manufacturers" \\
\hline Copyright or trademarks & $24 \%$ & $28 \%$ \\
\hline Secrecy & $12 \%$ & $19 \%$ \\
\hline Supply agreement & $18 \%$ & $26 \%$ \\
\hline Reaching the market first & $6 \%$ & $15 \%$ \\
\hline Patents & $24 \%$ & $27 \%$ \\
\hline
\end{tabular}

Figure 9: Protections of inventions. 
The "Building Material Suppliers" do not give the impression of being a line of business in the front line of innovation, rather the contrary. They are lagging by all comparisons.
So far the diagrams have showed parts of processes. The following diagrams, however, are more related to performance. Change in use of technology is shown in Figure 10.

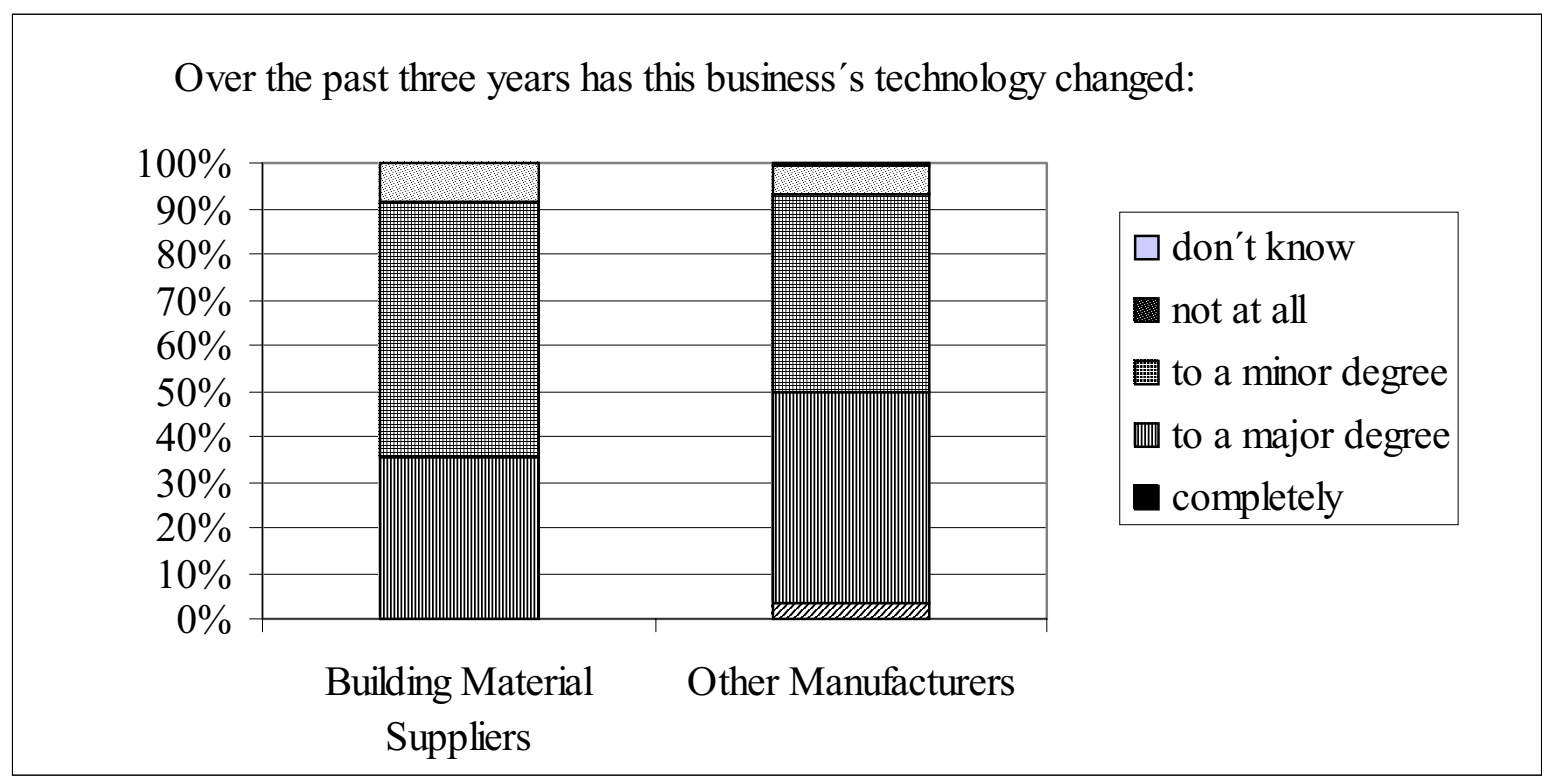

Figure 10: Change of technology.

As can be seen, there is a difference between the "Building Material Suppliers" and the "Other Manufacturers". Major changes have been effected among $46 \%$ of the companies in the group of "Other Manufacturers" and 35\% of the "Building Material Suppliers", while it was the other way round for minor changes. Among the "Building Material Suppliers" $56 \%$ of the companies had carried out minor changes and $43 \%$ of the "Other Manufacturers".

What do the figures tell us concerning the use of management and operating systems? Have the systems changed to follow development of the environment? Change of management and operating systems are shown in Figure 11.

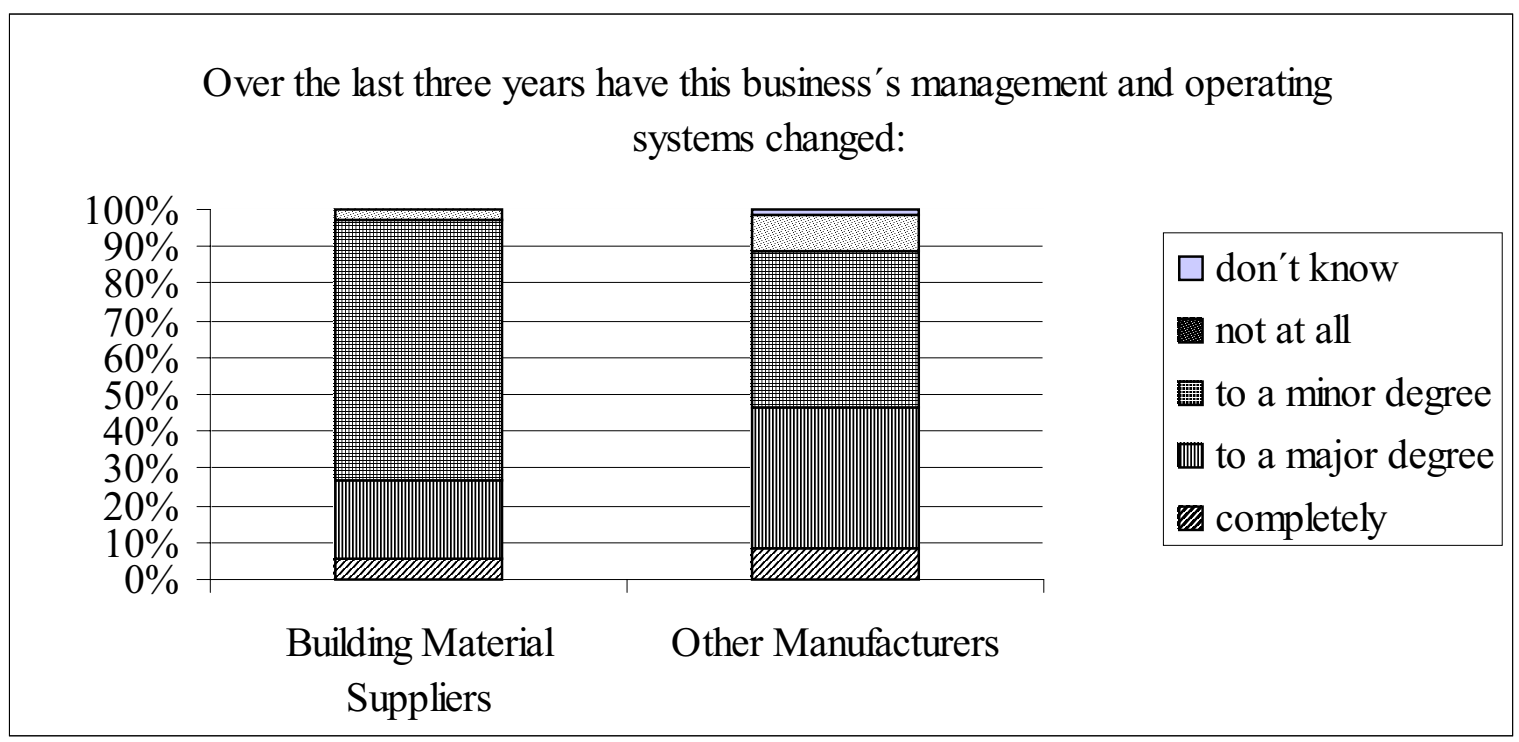

Figure 11: Changes in management and operating system. 
In Figure 11 the findings are similar to those found in Figure 10, but the differences are bigger. The companies in the OM group have effected bigger changes in their operating systems than the BMS have. We notice major changes or completely changed at $47 \%$ of the OM companies and $28 \%$ of the BMS. Minor changes were found among $71 \%$ of the "Building Material Suppliers" and $42 \%$ of the "Other Manufacturers". The "Building
Material Suppliers" seem to be less active than the group of "Other Manufacturers".

Punctuality, timelines and reliability are often discussed from a view of quality and customer satisfaction. To what extent the companies meet with promised deliveries is shown in Figure 12.

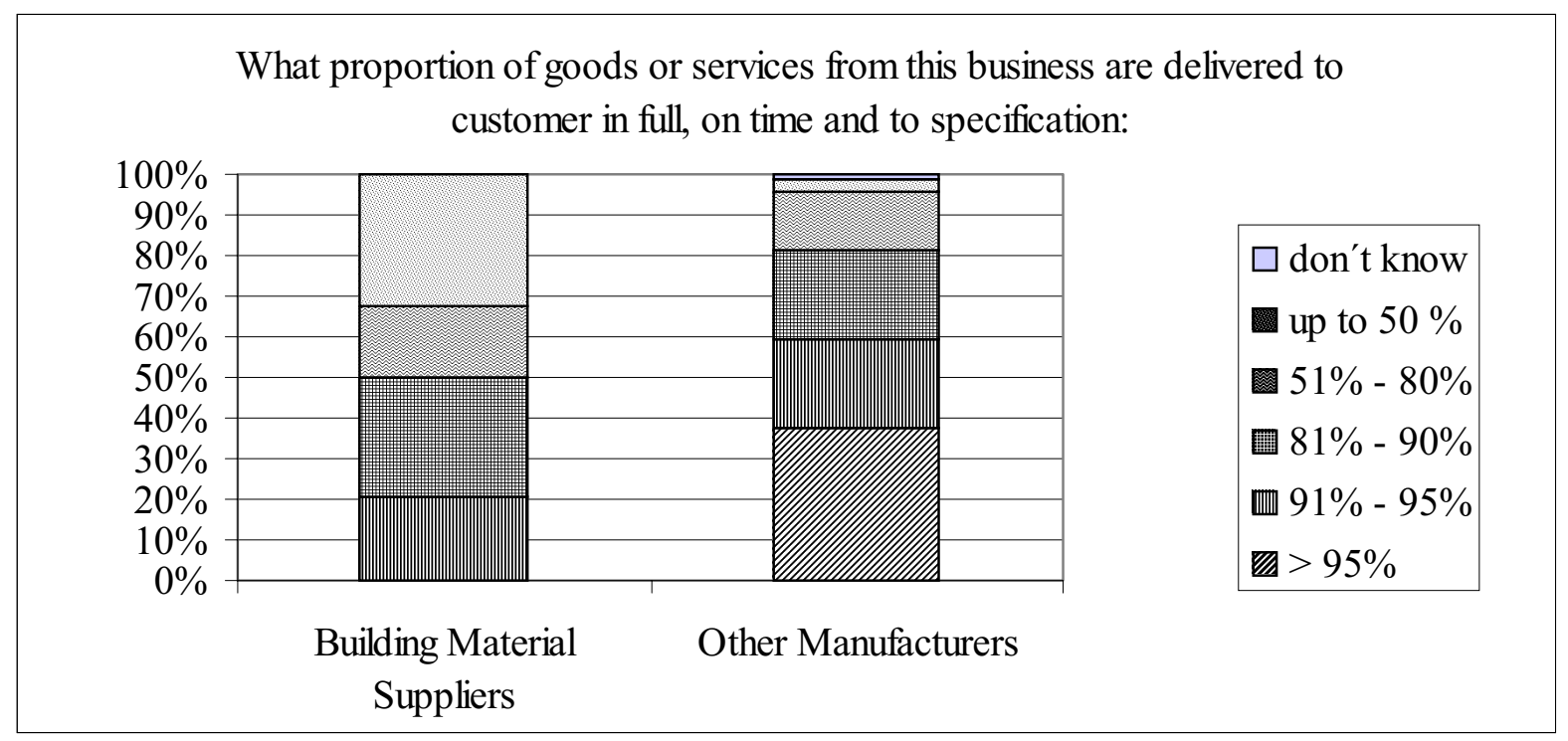

Figure 12 Correct deliveries.

More than $95 \%$ correct deliveries are achieved by $37 \%$ of the companies in the group of "Other Manufacturers". But none of the "Building Material Suppliers" reach this result. What do 95\% correct deliveries really mean? Is it really a fantastic figure or not? It means that 19 deliveries out of 20 are delivered to the customers in full, on time and according to specifications. It is something to strive for, when companies give priority to the customers. The diagram tells us that $20 \%$ of the BMS compared to $60 \%(37 \%+23 \%)$ of the OM companies achieve $91 \%$ correct deliveries.

\section{SUMMARY OF DIFFERENCES}

The following lines are a brief summary of the differences found in the article. For details please read "Findings from the Survey"

- A smaller share of the "Building Material Suppliers" than of the "Other Manufacturers":

- Offer new or significantly improved products.

- $\quad$ Invest in R \& D, machinery and equipment, marketing and employee training.

- The "Building Material Suppliers" have a greater share of their sales from older products than the "Other Manufacturers".

- The "Building Material Suppliers" have older equipment than the "Other Manufacturers".

- The BMS have poorer production processes and they are not as good at finding new ideas.

\section{CONCLUSION}

In this paper it has been shown that the innovation level is low among the "Building Material Suppliers". We have seen that a low innovation level can be quite logical to the suppliers, but not when compared to other trades. There is a need to understand more of the logic within the trade. This is important for us, in order to overcome the barriers that affect the motivation to innovate and therefore also could affect not only the contractors' productivity but also that of the whole industry. This barrier to development and innovative processes should be further investigated.

\section{REFERENCES :}

Andersson et al. (1983). Krävande företagsledning. Liber Förlag, Lund.

Barrett, P., Sexton, M. G. (2003). A literature synthesis of innovation in small construction firms: insights, ambiguities and questions. Construction Management and Economics, 21,

pp. 613-622

DIST. (1998). Building for growth: A draft strategy for the building and construction industry. Department of Industry Science and Tourism. Canberra, Commonwealth of Australia. 
Firm Foundations. (2002). A Study of New Zealand Business Practices \& Performance. Ministry of Economic Development, New Zealand.

Gann, D. M., Salter, A. J. (2000). Innovation in project-based, serviced-enhanced firms: the construction of complex products and systems. Research Policy, 29 (7,8), pp. 955-72.

Gearing up. (1999). A Study of Best Manufacturing Practice in New Zealand, Ministry of Commerce, New Zealand.

Larsson, B., Sundqvist, J. (2003). How to Collect Ideas for the Development of Product and

Process Innovations in the Building Process. Two Case Studies. Knowledge Construction, Proceedings of the Joint International Symposium of CIB Working Commissions W55,

pp. 408-414.

Leading the way (1994). Ministry of Commerce, New Zealand.

Lenard, D. J. (1996). Innovation and industrial culture in the Australian construction industry: A comparative benchmarking analysis of critical cultural indices underpinning innovation. Unpublished PhD Thesis, University of New Castle, New Castle.

Loosemore, M., Choo, H., Koh, H. (2002). Encouraging R\&D in construction. ASCE Journal of professional Issues in Engineering Education and Practice, 128 (1), pp. 25-30.

Loosemore, M. (2004). Impediments to reform in the Australian Building and Construction Industry. The Australian Journal of Construction Economics and Building, 3, no2.

Persson, Wirmark, M., Wijkman, P., M. (2002).

Tillverkningsindustrins konkurrenskraft i

Göteborgsregionen, Gothenburg Business School, Gothenburg University, Gothenburg.

Sundqvist, J. (2002). Insikter för framgång. ESI, Örebro University, Örebro.

Sexton, M., Barret, P. (2003). A literature synthesis of innovation in small construction firms: insights, ambiguities and questions. Construction Management and Economics, 21, pp. 613-622.

SOU 2000:44. (2000). Från byggsekt till byggsektor byggkostnadsdelegationens betänkande. Statens offentliga utredningar , Stockholm.

Winch, G., M. (2003). How innovative is construction? Comparing aggregated data on construction innovation and other sectors - case of apples and pears. Construction Management and Economics, 21, pp. $651-654$. 